\title{
Performance Analysis of a Full - Duplex WDM-EPON based System with Fiber to Wireless Optical Network
}

\author{
Pushplata Tiwari \\ M.Tech scholar \\ Dept. of ECE \\ SHIATS, ALLAHABAD
}

\author{
A.K.Jaiswal \\ Professor and \\ H.O.D \\ Dept. of ECE \\ SHIATS, ALLAHABAD
}

\author{
Neelesh Agrawal \\ Asst. Professor \\ Dept. of ECE \\ SHIATS, ALLAHABAD
}

\author{
Navendu Nitin \\ Asst. Professor \\ Dept. of ECE \\ SHIATS, ALLAHABAD
}

\begin{abstract}
Wireless technique is speedily becoming more essential during last four decade. Optical wireless channel is a type of communication in which unguided visible, IR, UV light wave is used to carry message signal. Based on transmission range optical wireless channel is used to send message at ultra-short, short, medium, high and ultra-high range. In this paper message signal is send through IR light wave at long range OWC from optical line terminal (OLT), having frequency lying in the range of $750 \mathrm{~nm}-1600 \mathrm{~nm}$. On the other hand single mode optical fiber is used at receiver end to carry signal to the optical network unit (ONU).In this paper it is demonstrated that WDM-EPON technology has been successfully deployed in fiber to home which makes system more advanced, cost effective and having very high bandwidth and very high data rate. The proposed bidirectional simulation is made on Optisystem software and analyzed considering Q- factor, BER and power received.
\end{abstract}

\section{Keywords}

OWC, WDM-EPON, Optisystem software. Fiber to ONUs,

\section{INTRODUCTION}

Present wireless communication demands high data rate, large $\mathrm{BW}$, low cost and flexible design due to progressively increasing number of subscriber. Subscribers require very HD video on demand and internet with high quality and guaranteed data delivery, so new technology is adopted for fulfilling these requirements. Audio, video, data signals are send through optical wireless channel (OWC).Optical communications are evolved from lengthy optical fibers to powerful wireless communications. Laser communication is now able to send Information at data rates up to several Gbps and covering distance up to thousands of kilometers. Another reason of using OWC is due to wavelength. RF wavelength is much longer compared to optical wavelength hence the beam width that can be achieved using lasers is narrower than that of the RF system and it can travel without much loss. The disadvantages of optical fiber communication like inconvenience being faced in physical connections are removed by Free Space Optical Communication. It is easy to deploy and can operate at high bit rates and Low bit error rates. It is license free and used for long range operation. But it has some ill effects like Atmospheric Absorption, Beam dispersion and Inference from background light sources. In wireless optical communication systems, light emitted directly from a fiber termination to free space through an optical antenna. At the receiver end, the transmitted optical beam is focused, using the receiver optics, directly to a fiber and then sent to the fiber for detection. The usefulness of free space optical communication systems are that they are capable of replacing Radio over Fiber links. Free space optic communication systems are a solution of the "last mile" Problem mainly in overpopulated urban areas. After introducing passive optical network in this system, it enhances the system developed network and offers more advance features. PON is an attractive method and provides the most cost-effective architecture for the network plant in delivering the radio signal. PON is quite reliable, easy to maintain, easy to install and power efficient. Gigabit-PON (GPON) and Ethernet-PON (EPON) are the most two popular PONs. EPON has been used in this paper.WDM is used for multiplexed different laser signal carry message signal over OWC. At the end of OWC a Single mode optical fiber is also used to carry the optical signal to the desired ONUs. This system is work as a FTTH(fiber to the home) type services in which optical fiber is used to send the messages to each ONUs for few $\mathrm{km}$ giving high bandwidth(up to $\mathrm{THz}$ ) at low attenuation $(0.2 \mathrm{~dB} / \mathrm{km})$.

\section{METHODOLOGY}

\subsection{Radio over Optical Wireless Channel}

Basically radio signal transmission is analog transmission system which is converted in to digital form by using PRBS generator (bit rate $2.5 \mathrm{Gbps}$ ) and NRZ modulation technique (sample rate $160 \mathrm{GHz}$ ).For optical modulation external modulation is used here, which is mach-zehnder modulator(M-Z modulator) in which a CW DFD laser array of four different wavelength of carrier signal (four different wavelength of laser signal) around the wavelength $1550 \mathrm{~nm}$ and frequency spacing $100 \mathrm{GHZ}$ and $5 \mathrm{dBm}$ power are used which is multiplexed by $\mathrm{WDM}$ (wavelength division multiplexing) having same frequency and frequency spacing as CW-DFD laser has. MZ modulator has very less dispersive effect. MZ modulator modulates the digitized RF signal with the help of multiplexed laser signal as shown in figure-1 and send through OWC.

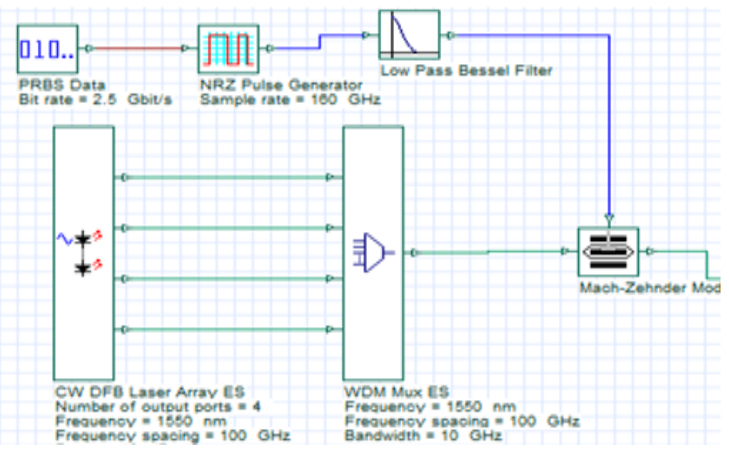

Figure.1 optical modulation using M-Z modulator 


\subsection{Ethernet passive optical network Architecture (EPON)}

An EPON consist of an optical line terminal (OLT) at service provider central office and optical network units (ONUs) at end users. EPON configuration reduces amount of fiber and equipment at central office. An EPON is point to multipoint communication system providing high speed network connection in which passive optical components (like AWG, power splitter, circulators) are utilized. Data rate of EPON both in upward and downward directions are $2.5 \mathrm{Gbps}$. At ONUs optical signals are converted back into radio signal and used by subscriber and also regeneration takes place which is feedback to the input side as downstream signal by the use of TDMA concept. The properties of EPON are given in table1 and EPON architecture shown in figure-2.

Table1: Properties of EPON

\begin{tabular}{|l|l|}
\hline Quantity rate & Value \\
\hline $\begin{array}{l}\text { Data rate } \\
\text { upstream) }\end{array}$ & $2.5 \mathrm{GBPS}$ \\
\hline $\begin{array}{l}\text { Data } \\
\text { (downstream) }\end{array}$ & $\mathrm{nm}$ \\
\hline $\begin{array}{l}\text { Wavelength } \\
\text { (upstream) }\end{array}$ & $\begin{array}{l}1550 \mathrm{~nm}, 1549.2 \mathrm{~nm}, 1548.2 \mathrm{~nm}, 1547.2 \\
\mathrm{~nm}\end{array}$ \\
\hline $\begin{array}{l}\text { Wavelength } \\
\text { (downstream) }\end{array}$ & 4 \\
\hline PON split & $100 \mathrm{~km}$ \\
\hline Max Distance & $\mathrm{nm}, 1548.2 \mathrm{~nm}, 1547.2$ \\
\hline
\end{tabular}

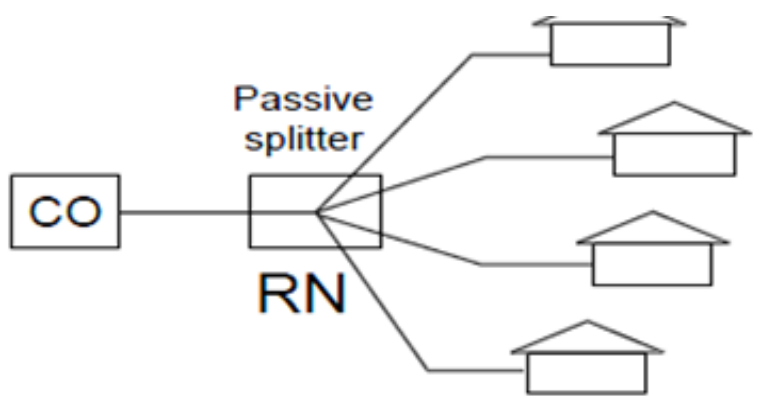

Figure. 2 EPON Architecture

\section{SIMULATION DESIGN}

In this section the simulation is done using optisystem-13.The design in fig-3 shows that the development of WDM-EPON based OWC transmission using four different wavelength of light. At OLT (optical line terminal) section, PRBS (pseudo random bit sequence) generator have $2.5 \mathrm{Gbps}$ data rate and NRZ pulse generator have $160 \mathrm{GHz}$ operating frequency and Cut-off frequency $1.875 \mathrm{GHz}$ goes to the $\mathrm{MZ}$ modulator where a CW DFD laser array having $5 \mathrm{dBm}$ power used to produce four different wavelengths. WDM is used to multiplex these different wavelengths and send via single channel. After that it modulates the digitized radio Signal with the help of MZ modulator. This optical modulated signal gets amplified by EDFA amplifier. Subsequently the amplified signal gets splitted by power splitter of $(1 \mathrm{x} 4)$ size. Circulator is used to pass these signals and it also takes the signal from ONU side and delay is given for proper circulation. A bidirectional 4x1 AWG is used after circulator; these signals of different wavelengths are again multiplexed and send with the help of OWC at $100 \mathrm{~km}$ in upward and downward direction. At receiver side these multiplexed signal get demultiplexed by using AWG of $1 \times 4$ sizes. The signal has to be send via four different single mode fibers at $1-30 \mathrm{~km}$ to its optical network unit to provide FTTH service. By using optical fiber at receiving end to the optical network units; very secured and high bit rate data is achieved. At ONU; APD photo detectors are used to convert optical signal into radio signal and passed through low pass Bessel filter which passes only information signal and block the unwanted signal. Again signals from this ONUs send back to OLT side by using the same procedure. At input side there are buffer selectors which select only single wavelength for their particular optical line terminals. The Hardware configuration is shown in table-2 and simulation diagram shown in fig-3.

Table 2: Simulation Parameter

\begin{tabular}{|c|c|}
\hline $\begin{array}{l}\text { Max } \\
\text { distance of } \\
\text { OWC }\end{array}$ & $100 \mathrm{~km}$ \\
\hline $\begin{array}{l}\text { PRBS } \\
\text { generator }\end{array}$ & Bit rate $=2.5 \mathrm{Gbps}$ \\
\hline $\begin{array}{l}\mathrm{CW} \text { DFD } \\
\text { laser array }\end{array}$ & $\begin{array}{l}\mathrm{P}=5 \mathrm{dBm}, \text { Wavelength }=1550 \mathrm{~nm}, \text { Frequency } \\
\text { spacing }=100 \mathrm{GHz}, \text { Bandwidth }=10 \mathrm{GHz}\end{array}$ \\
\hline $\begin{array}{l}\text { Photo } \\
\text { detector } \\
\text { APD }\end{array}$ & $\begin{array}{l}\text { Responsivity }=1 \mathrm{~A} / \mathrm{W} \\
\text { sample rate }=5 * \text { sample rate }\end{array}$ \\
\hline $\begin{array}{l}\text { NRZ pulse } \\
\text { generator }\end{array}$ & Sample rate $=160 \mathrm{GHz}$ \\
\hline $\begin{array}{l}\text { Low pass } \\
\text { Bessel filter }\end{array}$ & $0.75 *$ bit rate \\
\hline $\begin{array}{l}\text { Bidirectional } \\
\text { AWG }\end{array}$ & 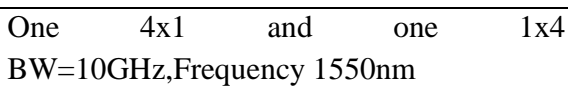 \\
\hline WDM & $\begin{array}{l}\text { Wavelength }=1550 \mathrm{~nm}, \text { Frequency } \\
\text { spacing }=100 \mathrm{GHz}, \text { Bandwidth }=10 \mathrm{GHz}\end{array}$ \\
\hline $\begin{array}{l}\text { Four buffer } \\
\text { selector }\end{array}$ & $\begin{array}{l}\text { Wavelengths }=1550 \mathrm{~nm}, 1549.2 \mathrm{~nm}, 1548.2 \mathrm{~nm} \text {, } \\
1547.2 \mathrm{~nm} .\end{array}$ \\
\hline $\begin{array}{l}\text { 4-Single } \\
\text { mode optical } \\
\text { fiber }\end{array}$ & $\begin{array}{l}\text { Attenuation }=0.2 \mathrm{~dB} / \mathrm{km}, \text { Max Length }=30 \mathrm{~km} \\
\text { Wavelength }=1550 \mathrm{~nm}, 1549.2 \mathrm{~nm}, 1548.2 \mathrm{~nm} \text {, } \\
1547.2 \mathrm{~nm} .\end{array}$ \\
\hline
\end{tabular}




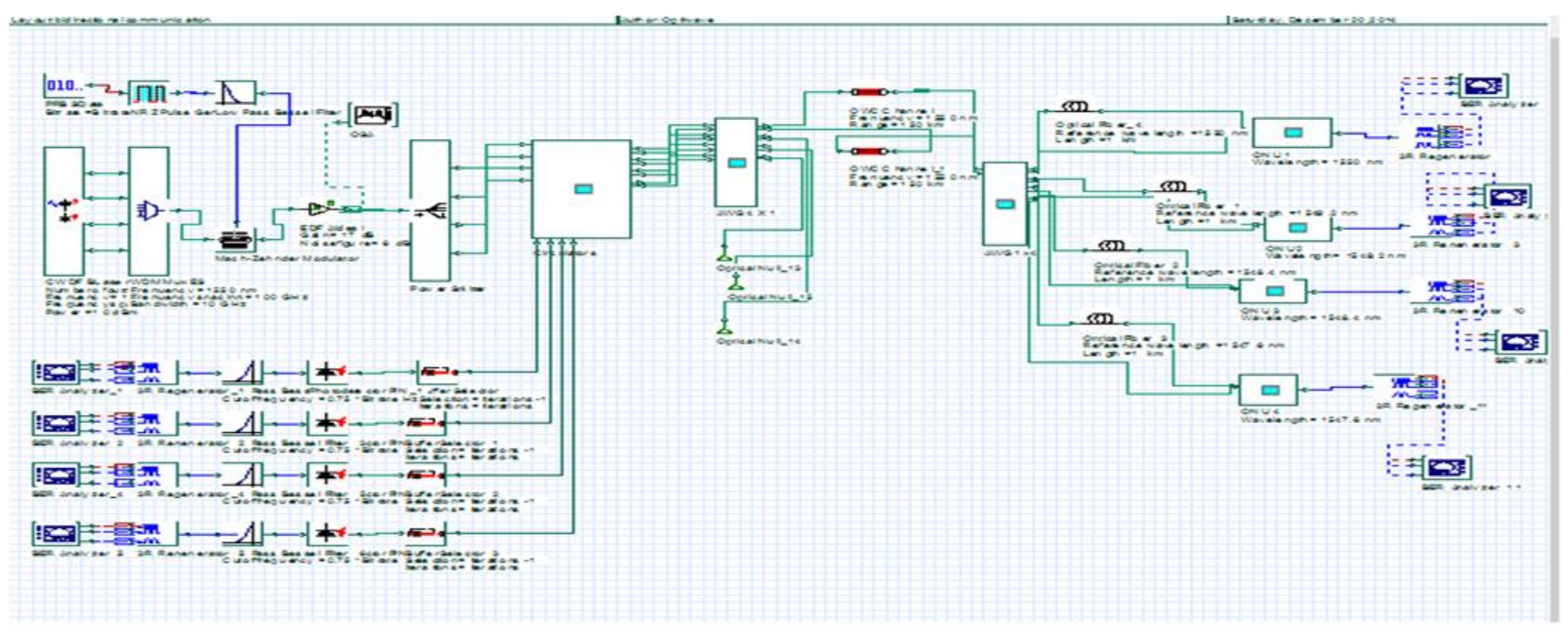

Figure 3: Simulation Design

\section{SIMULATION RESULT AND ANALYSIS}

On the basis of above design, simulation is done and the analysis of system is presented. The same performance for upstream and downstream are presented and the results are different for four different ONU's and four OLTs. Spectrum of RF signal, modulated signal before and after OWC, Qfactor, BER of signal and demodulated output RF signal are plotted in figures shown below.

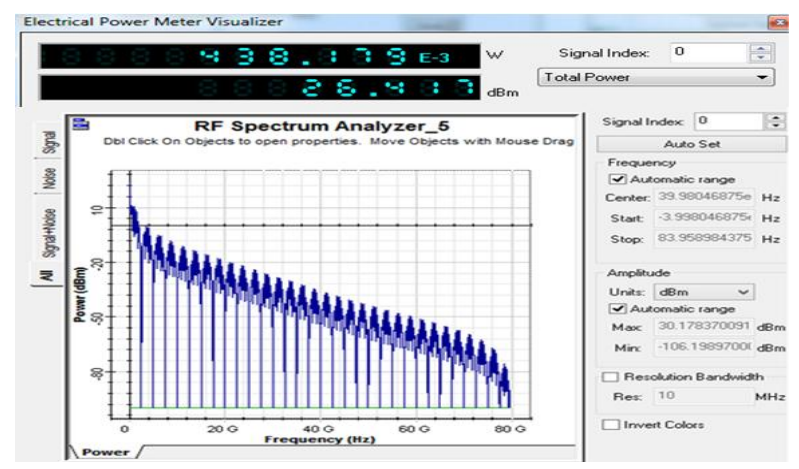

Figure 4 :Spectrum of RF signals

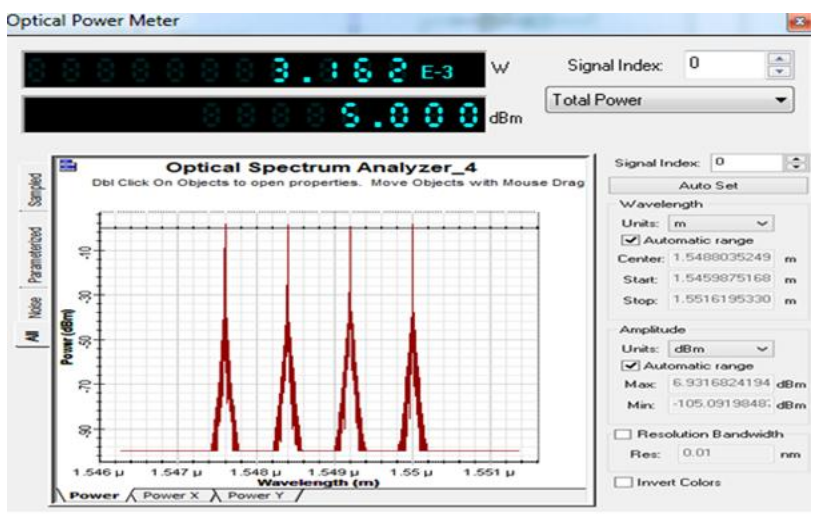

. Figure.5: The spectrum of WDM - CW laser
The figure 4 is baseband signal which has to be sent via OWC. The message signal has electrical power of about $26 \mathrm{dBm}$.Fig-5 shows array of laser light of four different wavelengths having optical power $5 \mathrm{dBm}$.



Figure 6: The spectrum before $100 \mathrm{~km}$ of $\mathrm{OWC}$.

Fig-6 shows the WDM signal passing through power splitter and array waveguide.

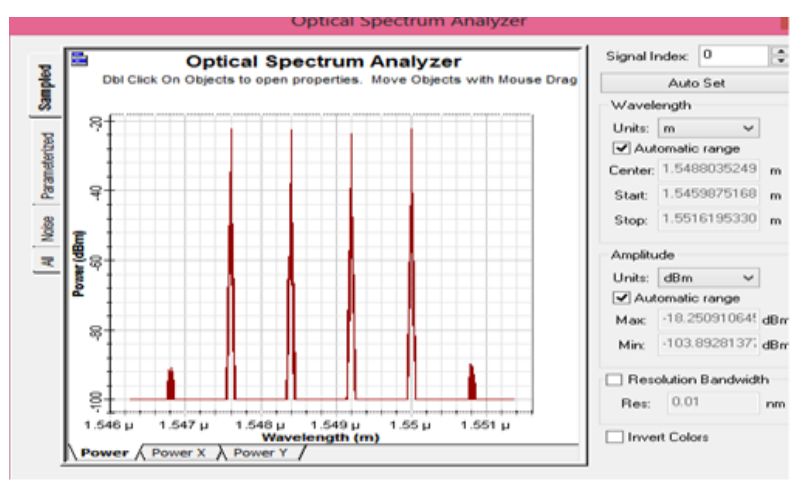

Figure 7: The spectrum after $100 \mathrm{~km}$ OWC.

Figure-7 shows the spectrum after $100 \mathrm{~km}$ of OWC. 


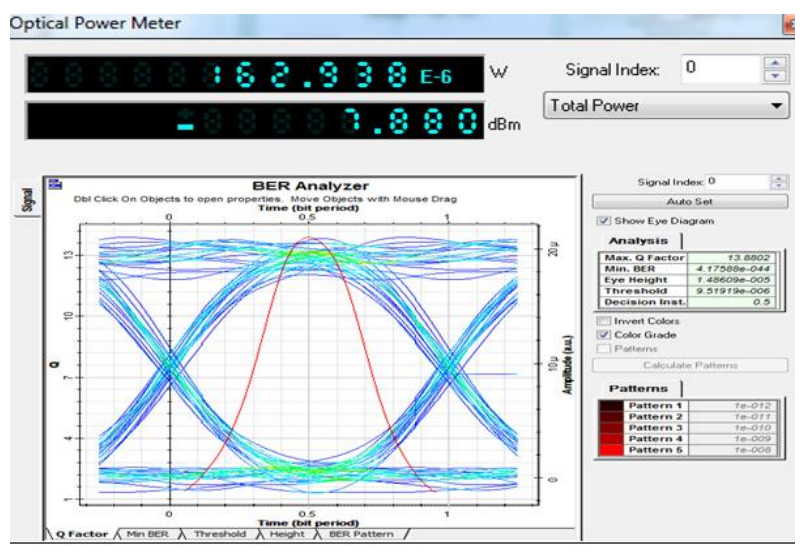

Figure 8: The Q-factor of the signal at ONU-1

The fig. -8 shows that the quality factor at ONU-1.It shows that very good opening of eye. The optical power at this ONU is about $-26 \mathrm{dBm}$.

Table -3 Parameters of eye diagramm at each ONUs

\begin{tabular}{|c|c|c|l|}
\hline $\begin{array}{c}\text { Maximum } \\
\text { q-factor }\end{array}$ & $\begin{array}{c}\text { Minimum } \\
\text { BER }\end{array}$ & Eye height & ONU's \\
\hline 13.8802 & $\begin{array}{c}4.71588 \mathrm{e}- \\
044\end{array}$ & $1.48609 \mathrm{e}-005$ & $\begin{array}{l}\chi_{1=} 1550 \mathrm{~nm} \\
\end{array}$ \\
\hline 13.9843 & $\begin{array}{c}9.62509 \mathrm{e}- \\
045\end{array}$ & $1.52819 \mathrm{e}-005$ & $\begin{array}{l}\chi_{2=} 1549.2 \mathrm{n} \\
\mathrm{m}\end{array}$ \\
\hline 15.8576 & $6.0725 \mathrm{e}-057$ & $1.56536 \mathrm{e}-005$ & $\begin{array}{l}\chi_{3=} 1548.2 \mathrm{n} \\
\mathrm{m}\end{array}$ \\
& & & \\
\hline 14.1856 & $\begin{array}{c}5.49046 \mathrm{e}- \\
046\end{array}$ & $1.50005 \mathrm{e}-005$ & $\begin{array}{l}\chi_{4=} 1547.2 \mathrm{n} \\
\mathrm{m}\end{array}$ \\
\hline
\end{tabular}

At each ONU the quality of signal is different. The q-factor, BER and the eye Height for each ONU's is given in the table3.

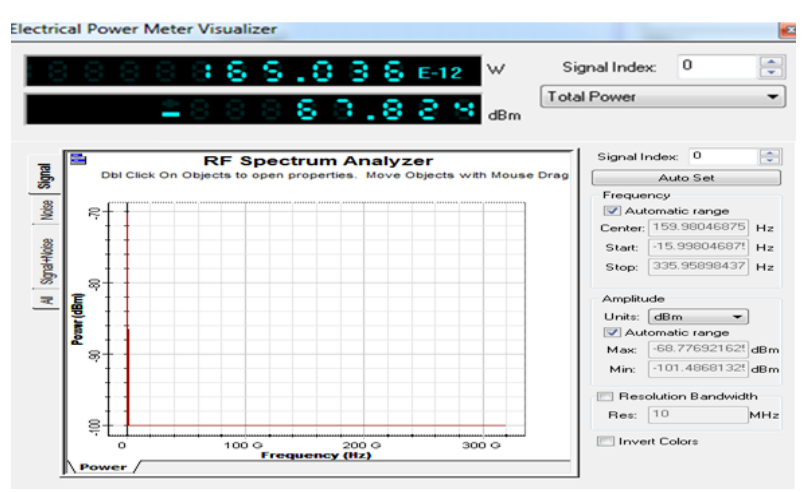

Figure 10: The demodulated Rf signal at ONUs

Analysing the spectrum it is obseved that the quality factor of signal at output of optical network unit which works on frequency $1550 \mathrm{~nm}$ is 13.8802 and min BER is $4.71588 \mathrm{e}-$ 044.the elcetrical power at transmitter is about $26 \mathrm{dbm}$ and after covering $100 \mathrm{~km}$ of OWC and $30 \mathrm{~km}$ of Optical fiber distance the power become at receiver side is about $-67 \mathrm{dbm}$ means there is total $93 \mathrm{dbm}$ electrical power loss in the message signal and total optical power decreases from $5 \mathrm{dBm}$ to $-26 \mathrm{dBm}$ means total optical power loss is about $31 \mathrm{dBm}$.

\section{CONCLUSION AND FUTURE SCOPE}

In this work the performance analysis of bidirectional WDMEPON over wireless optical network has been made . Lower BER, higher Q-factor at the output besides good power budget is obtained. Due to very high operating frequency, high data rate, and large bandwidth WDM EPON is very good choice for wireless internet user. As the distance between transmitters and receiver is increased the power loss also increases. From the above analysis it is clear that the BER and Q-Factor also depend upon operating frequency of ONU's. Further work may be initiated where in the number of information signal send together at input side with the help of separate modulation for getting number of message signal at receiver side.

\section{ACKNOWLEDGEMENTS}

I would like to thanks my advisor prof. A.K. Jaiswal H.O.D,SSET, Sam Higginbottom institute of agriculture technology and sciences (deemed-to-be university), Allahabad, for providing guidance and all require facilities and thank to my co advisor Neelesh Agarwal assistant professor, SSET, for their constant co-operation, help, guidance and support during project period.

\section{REFERENCES}

[1] Affida M. Zinet al, (December 2011.)The Characterization of Radio over-Fiber Employed GPON Architecture for Wireless Distribution Network, Member, IEEE International Journal of Machine Learning and Computing, Vol. 1, No. 5.

[2] Akhil Gupta et al, (November 2014), Survey of Free Space Optical Communication Network Channel over Optical Fiber Cable Communication .International Journal of Computer Applications (0975 - 8887) Volume 105, No- 10.

[3] A. V. Osadchiv et al, "Converged Delivery of Wi-Max and Wire line Services over an Extended Reach Passive Optical Network", Journal of Optical Fiber Technology, Vol. 16, p. 182-186.

[4] B.Glushko Gigabit optical wireless communication System for personal area networking OpticalDep.,boris,glushko@ rittech.com; D.Kin, Mechanical [15] Dep., david.kin@rittech.com; A.Shar, R\&D Dep., alex.shar.@rittech.com; RIT Technology LTD, Tel-Aviv, Israel

[5] Bikram Beri1 et al, wdm based fso link optimizing for $180 \mathrm{~km}$ using bessel filter ijret: International Journal of Research in Engineering and Technology eISSN: 23191163 | pISSN: 2321-7308 Volume: 03 Issue: 03 | Mar2014, Available @ http://www.ijret.org.

[6] Dr. Ali Mahdi Hammadiet al, (February-2014) Transmission Performance Analysis of Three Different Channels in Optical Communication Systems. International Journal of Scientific \& Engineering Research, Volume 5, Issue 2, 1615 ISSN 2229-5518 IJSER.

[7] Gangxiang Shen, et al, (Aug. 2007) "Fixed Mobile Convergence Architectures for Broadband Access: Integration of EPON and WiMAX”, IEEE Communication Magazine. 
[8] Isha Aggarwal, et al, (2013), Performance Evaluation of Intersatellite Free Space Optical Communication System with Varied Parameters and Transceiver Diversity Advance in Electronic and Electric Engineering. ISSN 2231-1297, Volume3, pp.847-852

[9] M. L.Bonilla et al, (2009) "Techno-Economical Comparison between GPON and EPON Networks", Proceeding of ITU-T Kaleidoscope Academic Conference.

[10] Resmi R. S.et al (2013) Investigations of Bit rates in Optical Intersatellite Wireless LinksInternational Journal of Science and Research (IJSR) ISSN (Online): 23197064 Index Copernicus Value 6.14.

[11] S. Lallukkaet al, (2005) "Link Utilization and Comparison of EPON and GPON Access Network Cost”, Proceeding of IEEE Globecome.
[12] S. Pato et al, (2008) "On Supporting Radio over Fiber and Passive Optical Network Systems with a Common Fiber Plant: Compatibility Aspects," Proceeding of ITCON.

[13] Sandeep(2014) Performance Analysis of Optical WirelessCommunication Link By Multiple Tx/Rx with and Without Amplifier Ajmer, India International Journal of Engineering Research \& Technology (IJERT ISSN: 2278-0181 Vol. 3 Issue 6,

[14] Tien-Thang Pham, Integration of Optically Generated Impulse Radio UWB Signals into Baseband WDM-PON

[15] Yogendra Singh et al, Performance Analysis of Optical Wireless Communication Channel Link at Various Bit Rates.International Journal of Computer Science \& Engineering Technology (IJCSET) 